the Corporation which operates its development activities in an area in which it is particularly difficult for the individual inventor to succeed. In many other industrialized nations industry is more receptive to new ideas and will generally take up innovations more quickly and enthusiastically than in Britain, or is prepared to take greater risks where final commercial viability is less easy to assess. The Corporation generally becomes directly involved where the technical possibility is more in doubt, the commercial prospects are difficult to assess, or where it appears that there may be a benefit to the community as a whole, and where the benefit to one branch of industry may be marginal.

There is no doubt that the individual inventor now has a difficult task and that in the scientific field the inventor is increasingly a highly qualified man working with adequate resources. True inventiveness should always be encouraged and in spite of the fact that the lone inventor now has a smaller chance of making significant seientific advances, if he does succeed in doing so he has a better chance than ever before of getting his ideas adopted, followed by fair treatment and financial reward.

\title{
THE EUROPEAN ORGANIZATION FOR NUCLEAR RESEARCH
}

\begin{abstract}
THE seventh annual report of the European Organization for Nuclear Research (CERN) * covers the period to the end of 1961 and gives a detailed account of the activities of the Organization during a year which Prof. V. F. Weisskopf, the director-general of the Organization, describes in his introduction to the report as "an exporimental year". It was the first year in which the research programme got into something approaching its full stride and in which tentative solutions wore tried out to the problems of internal organization, of the shaping and management of the programme itself, and of relationships with other research organizations and research physicists.
\end{abstract}

The staff on December 31, 1961, numbered 1,091, of whom 187 wore scientists and engineers, 573 technicians, 149 administrative and 182 ancillary members. They were organized in twelve divisions under a directorate of three and the director-general. The total expenditure during 1961 amounted to $70 \cdot 2$ million Swiss franes, of which 36.2 million was devoted to eapital expenditure, mainly on buildings and on the accelerators and experimental equipment; 8.4 million on general expenditure; and 25.6 million on staff salaries and expenses.

The mean intensity of the proton synchrotron remained at about $2.5 \times 10^{11}$ protons/pulse with a trapping efficiency of 50 per cent. The machine time allocated to nuclear physics experiments increased by about 50 per cent, from $62 \mathrm{~h}$ per week during January to $93 \mathrm{~h}$ per week during October. About 15 per cent of the total machine time was lost through various breakdowns. The commissioning during August of a new experimental hall (North Hall) made room for two extra beams to be set up, making a total of five beams in use round the machine at the end of 1961 .

Two CERN-designed el $\epsilon$ ctrostatic separators came into operation during the year. A voltage of $750 \mathrm{kV}$ could be held over a gap of $14 \mathrm{~cm}$ in a 3-4 GoV/c. antiproton beam and of $500 \mathrm{kV}$ over a gap of $8.5 \mathrm{~cm}$ in a $1.5 \mathrm{GeV} / \mathrm{c} . \mathrm{K}^{-}$ beam. Other new separators, including a radio-frequency separator, are under construction.

The research performed by mombers of the Nucloar Physics Division with the proton synchrotron was very fruitful. In the section of the report dealing with the activities of this Division, 16 experiments with the proton synchrotron and 11 with the synchro-cyclotron are describod in some dotail. For the proton synchrotron these include elastic and near-elastic scattering of protons on protons; total cross-section measuremonts of highenergy pions on hydrogen; strange particle physies; the measurement of resonances in the two-pion system using a spark chamber; the determination of the lifetime of the neutral pion. about $2 \times 10^{-16}$ sec; muon electron scattering; and the search for magnetic monopoles. Long experiments were performed with the help of two large French bubble chambers. 300,000 photographs were

* CERN, European Organization for Nuclear Research. Annual Report for 1961. 'Pp. 153. (Geneva: CERN, 1962.) taken with the 81-cm Saclay hydrogen bubble chamber in a beam of slow antiprotons and 80,000 pictures by the same chamber in a fast $(3 \cdot 0-4 \cdot 0 \mathrm{GoV})$ antiproton beam. (It was in the latter series of pictures that for the first time. early in 1962, a charged anti-Xi particle was found.) Interesting results were also obtained in the study of photographs taken with the 30 -cm hydrogen bubble chamber.

The experiments with the synchro-cyclotron included the outstanding experiment to measure the magnetic moment of the muon to an accuracy of 1 in 200,000 , thus establishing that the muon is accurately described as a Dirac particle with no interaction other than the electromagnetic and the weak kinds - that is, that it bohaves exactly as a heavy electron. During 1961 an experiment on the scattering of negative $\mu$-mesons on $C$ was started, and the reaction $\mu^{-}+p \rightarrow n+\nu$ was investigated directly without nuclear complications in the Italian 20 -cm hydrogen bubble chamber. The energies of $\mu$-mesic X-ray transitions $(2 p-1 s$ and $3 d-2 p)$ were measured for many nuclei throughout the Periodic Table, and the search for the neutrino-less conversion of a muon into an electron using an improved $\mu^{-}$beam intensity and a spark chamber has continued.

Using a modular system of construction, the Electronies Workshop has produced a comprehensive range of transistorized nucleonic instruments for use in the nuclear physics experiments. The range includes a fast triple coincidence circuit, fast discriminator, 5-way splits, dəlays and triggers, $100-\mathrm{Mc} / \mathrm{s}$ pre-scaler, fast-pulse amplifier with a gain of 10 and rise of 2 nsec, and pulse burst generators. Some work has been initiated in the field of image intensifiers and scintillation chambers.

During the year under review it became clear that more attention would have to be given to data handling and analysis, and that more and more machine time would be required from computers with faster operation and larger memories. The introduction of a 709 computor has greatly increased the computing facilities; but the absence of a link between the 709 and the Mercury computer has been the main bottleneck. A number of general-purpose programmes have been added and an improved compilor has been introduced to simplify tho testing of Autocode programmes.

The staff of the Theoretical Study Division at the end of 1961 comprised ten scientists, one computer-programmer and two secretaries. In addition. about thirty theoreticians under tho CERN and Ford Foundation fellowship programmes were working at any one time in the Division. Various problems characteristic of the very-high-energy region opened up by the CERN proton synchrotron were given special attention. Near-elastic scattering of nucleons on nuclei, inelastic nucleon-nucleon scattering with very small energy loss, and the interactions of high-energy neutrinos with complex nuclei, were the main subjects of study. A variety of problems relating to the physics of pions and nucleons and of strange particlas have also been investigated. The Theoretical 
Study Division organized an international conference at CERN on the theoretical aspects of very-high-energy phenomena during June $5-9,1961$. The proceedings were published as CERN Publication 61-22.

The Film-badge Service of the Health Physies Group monitored 1,069 people for $\gamma$-radiation, and in addition about 140 people were also under neutron film-badge control. Only 78 people received a dose exceeding 1 rem for the year. In seven cases the maximum permissible annual exposure of 5 rems was approached. Arrangements for making blood tests of people exposed to radiation were improved and extended. A monitoring system for all waste leaving the CERN site has been set up. Routine weekly surveys of the radiation-level from the proton synchrotron and from the synchro-cyclotron were made.

Careful consideration was given during the year to the question of the rate of growth of the Organization in the future. The Council agreed on a budget for 1962 which would permit a moderate rate of growth and decided that during 1962 a more profound study should be under. taken by a special working party of the basic questions on which any policy for the future should be founded. Provision was made in the budget for 1962 for an intraEuropean study-group to produce design studies of two possible future projects, a storage ring device to be fed from the present proton synchrotron and $a_{3} 300-\mathrm{GeV}$ highintensity proton synchrotron. The device is likely to consist of two storage rings of the same size as the proton synchrotron, but with d.c. magnets with split focusing and bending. The r.f. system would also be smaller and more delicate. The cost is estimated to be less than twice the cost of the proton synchrotron and the construction time about five to six years.

Because of a serious shortage of staff in the Public Information Office the production of the CERN Courier had to be practically suspended and many other activities were greatly handicapped. Four television programmes and ten radio programmes were arranged. English, French and Italian versions now exist of the CERN film Matter in Question, which was awarded the Grand Prix in its class at the International Festival of technical and scientific films in Budapest. A German version is to follow during 1962. A total of 5,867 people in 206 conducted parties were shown around the establishment, and a new scheme of visits is being worked out to allow visitors still to see as much as possible although the accelerators are now practically inaccessible. The separate report of each Division concludes with a list of publications by members of the Division, and in two appendixes to the annual report are listed the 1961 CERN publications; reprints of publications during 1961 in other periodicals by members of the staff of CERN; and details of the lectures, seminars and colloquia held at CERN.

S. WEINTROUB

\section{RECENT DEVELOPMENTS IN ASTRONOMIC AND SPECTRONOMIC INSTRUMENTS}

$\mathrm{W}$ ORK undertaken during 1962 by Sir Howard Grubb Parsons and Co., Ltd., has included a number of interesting and unusual projects. A 48-in. reflecting telescope has been erected at the Victoria Observatory, British Columbia, and a rather uncommon type of telescope, a twin 16-in. reflector, has been manufactured for the Royal Observatory at Edinburgh. Each tube of the twin reflector contains a 16-in. primary mirror and a Cassegrain mirror giving an overall focal ratio of $f / 15$. One of the tubes can be off-set from the other in any direction up to $5^{\circ}$ and simultaneous photometry can be carried out on two stars. The operation of the telescope can be made fully automatic.

Because of difficulty in obtaining acceptable glass blanks for the eomponents of the complex optical system for the 40-in. reflector for the Cape Observatory, the completion of the telescope has been held up. The optical system uses a parabolic mirror and a lens system affording a wide field of good definition at the prime focus. A large correcting plate is located at about the prime focus and a correcting lens is inserted in the beam just before it comes to a focus. When the optical system is assembled it will be necessary to mount it in the telescope tube and test it in the tube. The test will be carried out in the test tower at the works. All the heavy items and fabrications for the 98-in. Isaac Newton reflecting telescope have been received and many of the machining operations have been completed.

Newly developed instruments include the 'Spectromaster', an infra-red spectrometer, covering a wavelength range of $0 \cdot 6-25 \mu$, and an interferometric spectrometer based on the work of Dr. H. A. Gebbie at the National Physical Laboratory. Now techniques have been developed to produce very narrow band interference filters for the visible and selective filters for the infre-red. For the U.K. Atomic Energy Authority establishment at Harwell, two remotely controlled gas analysers to monitor carbon monoxide and carbon dioxide in a helium test loop for Pluto have been made, and four glass windows have been polished for use in a liquid hydrogen bubble chamber. Four oval windows for a similar purpose are to be ground and polished for use by the European Organization for Nuclear Research (CERN). Measuring $70 \times 25 \times 6$ in. and weighing approximately 1,300 lb. each, they will constitute the largest pieces of optical glass ever to be manufactured anywhere in the world.

\section{PAL/EONTOLOGY IN THE U.S.S.R.}

ONSIDERABLE advance has been made in palæon-
tological research in the U.S.S.R. during the past
half-century, following on the great development in this
field of scientific activity in Russia during the nineteenth
century. Characteristic of the present-day approach is the
re-orientation of palæontology so that it is no longer treated
as a mere annex of stratigraphy but is linked more closely
with biology (theory of evolution, ecology, geological
facies and conditions of fossilization). The Palæontological
Society, founded in 1916, has actively sponsored this research and much has been done by the numerous geological institutes and the universities. Publication has been covered by various scientific periodicals, more particularly the four series-Palceontology of the U.S.S.R., Problems of Palceontology, Palceontological Journal and Transactions of the Paloeontological Institute.

The old-type description of fossils, collected by overworked geologists, is replaced by planned systematic work, specially organized to combine field and laboratory investigations. Examples of such work can be seen in 